\title{
Fight over Italian research policy threatens chance for reform
}

[ROME] As Italy goes into its traditional August torpor, a struggle over who controls national research policy and the allocation of research grants threatens to undermine what could be the country's last opportunity for effective reform of its research structures.

The fighting has been most bitter over the future control, and indeed the veryidentity, of the National Research Council (CNR), which could see some of its responsibilities for biomedical research re-allocated to a new national institute (see below).

The opportunity for reform was provided by the 'Bassaninilaw', passed by parliament in March this year. The law, named after minister of public affairsFranco Bassanini, gives the government the right to modify existing laws without formal parliamentary approval in order to improve efficiency in all Italy's public institutions (see Nature 386, 208; 1997).

For research, this law opened the possibility of achieving quick solutions to deeply entrenched problems, such as the lack of both long-term research planning and transparent systems of peer review. But conflict between different ministries with interests in research, as well as within the research community itself, has meant that little progress has been made in the past six months - a serious problem, as all decrees prepared under the Bassanini law must be issued before next March.

As a first step in drawing up the new decrees, a working group headed by Giuseppe Tognon, undersecretary of state for research in the ministry of universities and research, catalogued the research activities of the different government-funded research organiza- tions, and made suggestions as to how they could be more efficiently grouped together.

In addition to the CNR, these agencies include the National Agency for New Technology, Energy and Environment (ENEA), the Italian Space Agency (ASI), the National Institute for Nuclear Physics (INFN) and the various clinical research institutes belonging to the ministry of health.

But in a document presented to the parliament last week, the working group went further than its initial brief to suggest a new system for planning research policy at government level, transferring considerable power from the CNR to the government. Under this proposal, a high-level advisory committee, the Comitato Nazionale per la Ricerca e la Tecnologia (CNRT), would draw up national research priorities. Its nine full-time members, drawn from the scientific and industrial research communities, would be nominated by the prime minister for four-year terms.

The committee would replace the current 25-strong Consiglio Nazionale Scienza Tecnologia (CNST), and, subject to the approval of the government's interministerial financial committee, would control the general distribution of a new interministerial fund intended, among other goals, to support strategic research lines of national interest. This new fund would eventually replace the funds currently allocated to CNR for targeted research.

In addition to the CNRT, eight or nine scientific research councils, to be known collectively as the Consigli Nazionali di Consulenza Scientifica (CNCS), would be established. These would take the place of the

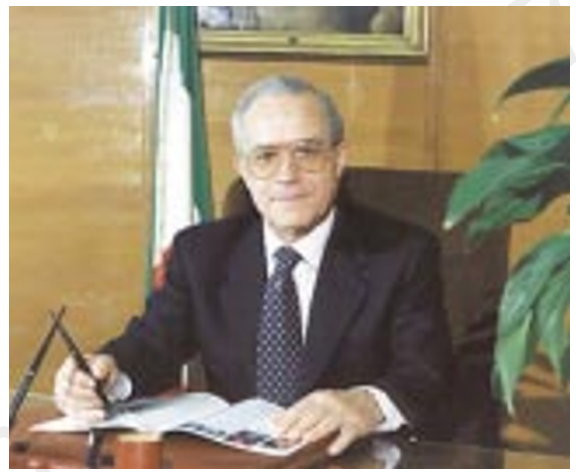

Bianco: research council needs reform, but must keep its role as "the scientific focus of Italy".

CNR committees, says Tognon. Their exact function remains undecided, but it will not be confined to CNR issues; for example, they are likely to take on responsibility for evaluating all government-funded research institutes.

Such a restructuring would severely curtail the activities and influence of the CNR. This was established in 1923 as primarily a scientific advisory agency reporting to the head of state and a funding agency for universities, but now embraces a portfolio of 195 research institutes and 137 research centres and groups housed within universities.

The CNR's 14 discipline-based committees have, over time, come to wield what many consider to be an unhealthy amount of power. They are responsible for distributing the CNR's investigator-initiated funds for university research, and nominate research directors of targeted projects and the project committees responsible for their evaluation.

\section{Government considers plans to create biomedical research institute}

[ROME] Another potential threat to Italy's National Research Council (CNR), as politicians consider the future shape of research funding (see above), is a proposal to create a National Institute of Biomedical and Clinical Research.

The ministry of health wants to link its 20 regional clinical research centres into a national institute coordinated by the Rome-based Istituto Superiore di Sanitá (ISS), the Higher Institute of Public Health.

This proposal, referred to in the research ministry's document on reform of the Italian research structure, presented to the cabinet last week, could depend on the outcome of a complete restructuring of the ISS.

In addition to its many research programmes, the 1,500strong ISS is burdened by many public health responsibilities dealt with by separate ministries.

The Bassanini law (see above) allows the government to rationalize these duties, and the health ministry is now discussing the creation of an independent agency, similar to the US Food and Drug Administration, to take over some of them.

Other ISS duties, such as those related to environmental toxicology, would also be transferred, leaving the ISS as the central institute of the proposed national network.

Giuseppe Benegiano, the new director of the ISS who took up office in May, opposes these moves. He supports the idea of a national institute but argues that it should retain its regulatory responsibilities. It makes sense financially to keep this within a restructured ISS "because we already have the infrastructure".

Many universities, as well as the research ministry, are concerned about the suggestion of a national institute for biomedical and clinical research for another reason: that it would put responsibility for the financing of clinical biomedicine firmly in the hands of the health ministry.

The CNR is worried that, once such a national institute is created, there would be political pressure to transfer CNR's own 20-odd biomedical research institutes to the new national body. "Researchers in these institutes want to stay in the CNR," says CNR president, Lucio Bianco.

Giuseppe Tognon, undersecretary of state for research, says that the controversy generated by the plan for a national institute suggests that the issue is likely to be resolved "in the long term rather than short term".

A. A. 
These committees are not obliged to operate a formal peer review system (though some do) or to follow defined rules for evaluation. Their activities are widely criticized as lacking transparency, although many defend them on the grounds that they are democratically elected by the entire academic community.

The heads of the committees form the decision-making Consiglio di presidenza (presidential council) which has considerable influence over the scientific direction of the CNR by choosing the targeted projects and controlling staff appointments. As a result, the CNR president has relatively little personal power.

There have been previous attempts to remove university research funds from the $\mathrm{CNR}$ and give them directly to the universities, in a bid to solve the problem of poor distribution. With the removal of its strategic funds, the CNR would lose its role as a funding agency, and be left as merely an organization running research institutes. Tognon argues that the CNR's strength "would remain research". But Lucio Bianco, the agency's new president, says that "it is not correct for CNR just to run institutes". While acknowledging that CNR needs reform, he thinks this should be an internal matter. "The CNR is the scientific focus of Italy, and it should not be stripped of its powers and responsibilities," he says.

Bianco wants the councils suggested by the ministry to be housed within the CNR, so that they will remain politically independent, and so that the CNR will maintain its "focus" role. He wants the agency role of the CNR to be maintained. But he also wants a clear separation between advisory committees and management functions, and wants to install an appropriate system of peer review.

Bianco insists that the CNR should retain its role as distributor of small grants to universities, but that these should no longer be spread thinly among all applicants. Tognon opposes these grants as "small dowries to each professor", but Bianco argues that they allow the CNR to "scout for new ideas" which would otherwise not find funding.

Bianco and Tognon at least agree on the fact that the CNR's many small research groups and institutes should be rationalized into bigger units. Bianco also wants to establish a new CNR governing body, whose mem- bers, he suggests, could be in part nominated by the research minister, and in part elected by the academic community. It is important that the CNR president has the casting vote in this body, he says.

Other research organizations have less to fear from the Bassanini reforms. ENEA, for example, is hoping that regulatory reforms will give it more flexibility. When nuclear research ended in Italy after the Chernobyl disaster, ENEA turned its hand to many new research directions — " "a thousand flowers bloomed”, says its president, Nicola Cabibbo — which it would now like to rationalize.

The CNR still has time to lobby in its defence. Although the decrees which finally emerge from the working document published last week will not require a parliamentary vote, parliament must give an opinion on the directions indicated in the document. Parliamentary discussion will take place in the autumn, and the government is likely to take any strongly supported objection seriously. Discussions may be prolonged and heated, which could threaten the whole point of the exercise - the issuing of decrees within the set time frame.

Alison Abbott

\section{Universities rally against cuts in Pentagon-funded research}

[WASHINGTON] A congressional committee has created alarm among many leading US research universities by calling for a major redirection of Pentagon money away from basic research, and for this money to be used to restore the sagging budget for developing and deploying new weapons systems.

The national security appropriations subcommittee in the House of Representatives has cut the Clinton administration's budget request for basic research at the Department of Defense (DoD) from $\$ 1.16$ to $\$ 1.03$ billion. The subcommittee argues that the military services need the money for weapons modernization.

The bill would transfer most of the money from the basic research budget, which is largely spent in the universities, to exploratory development, which is done in the DoD and industrial laboratories.

News of the proposed cut alarmed universities, which are more heavily dependent on DoD funds than is sometimes realized. The Massachusetts Institute of Technology, for example, gets about $\$ 60$ million a year from DoD - one-fifth of all of its research funds, or about the same as it gets from the National Institutes of Health. Predictably it is the engineering and computer science departments that rely most heavily on DoD money.

University representatives meeting in Washington last week agreed to fight the House plan during the congressional recess, in the hope that it will be rejected when conferees from the House and the Senate finalize a budget bill in September.

George Leventhal, an official at the Association of American Universities (AAU), which represents the 50 leading research universities, says that they hope to get support from defence contractors for the basic research programme.

University representatives deny that the DoD basic research account has received what the subcommittee describes as "neverending budget growth", pointing out that it has fallen steadily from $\$ 1.4$ billion in 1993 to $\$ 1.1$ billion this year.

Taking a longer perspective, however, the Pentagon has held its spending power in

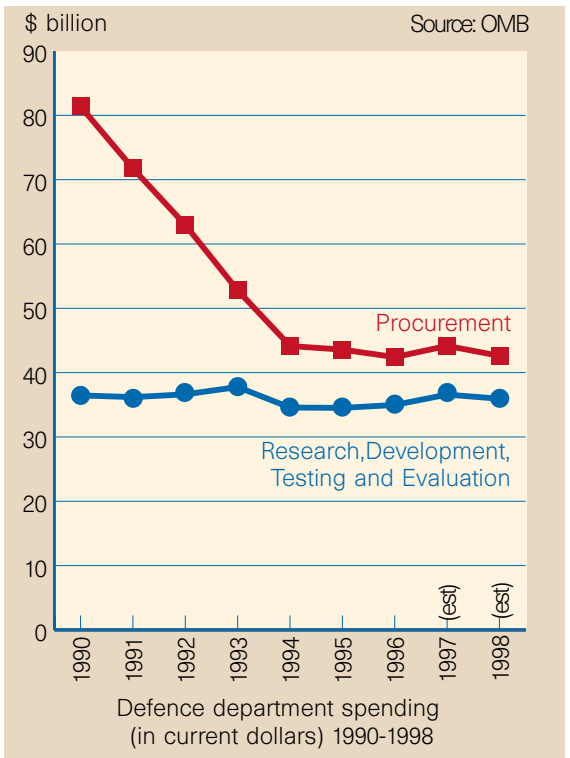

basic research at a level of around \$1.1 billion since 1990, during which time its much larger expenditure on research, development, test and evaluation (RDT\&E) has slipped in value by one-quarter.

During that period, the Pentagon's procurement of new equipment has nosedived, alarming defence hawks in the Congress. In the 1980s, procurement usually exceeded RDT\&E by a factor of three to one. This year, the two items are close to parity \$36 billion for RDT\&E and \$44 billion for procurement of equipment (see diagram).

The Clinton administration had supported a substantial increase in basic research spending this year, arguing that long-term research is a cost-effective way of ensuring the nation's military strength. The Senate appears to accept this, but the House may not.

In a barbed comment aimed at research spending, the language in the House bill complains of cuts in "defense medical programmes, training and readiness accounts, and other programmes such as munitions which have direct and immediate relevance to war-fighting needs".

Universities will try to meet members of Congress, including Bill Young (Republican, Florida), chair of the House appropriations subcommittee, during the recess. They will argue that substantial issues are at stake not just for the universities but for national security, and that the amount of money saved is small compared with procurement and other defence needs. 